\title{
Epoch Sequence Number
}

National Cancer Institute

\section{Source}

National Cancer Institute. Epoch Sequence Number. NCI Thesaurus. Code C93826.

An integer specifying the relative sequential or temporal ordering of this epoch among other similar epochs in a study. 